\title{
Birth-Related Activation of Preprotachykinin-A mRNA in the Respiratory Neural Structures of the Rabbit
}

\author{
MEERA SRINIVASAN, YUJI YAMAMOTO, HÅKAN PERSSON, AND HUGO LAGERCRANTZ \\ The Nobel Institute for Neurophysiology [M.S., Y.Y., H.L.] AND Department of Medical Chemistry [H.P.], \\ Laboratory of Molecular Neurobiology, Karolinska Institutet and Department of Pediatrics, Karolinska Hospital \\ S-104 01, Stockholm, Sweden
}

\begin{abstract}
The perinatal ontogeny of preprotachykininA gene expression was assessed in central respirationrelated structures. On the day of birth, there was an enhanced expression of preprotachykinin-A mRNA in the region of the nucleus tractus solitarii, the primary relay station for respiratory and cardiovascular reflexes. This increased expression was also seen in the pups delivered by cesarean section and allowed to breathe for a couple of hours as compared with their littermates, which were not allowed to breathe at all. On the basis of this finding, we suggest that the commencement of continuous breathing at birth, unlike the episodic breathing of fetal life, is associated with the enhanced expression of preprotachykinin-A mRNA in the nucleus tractus solitarii. (Pediatr Res 29: 369-371, 1991)
\end{abstract}

\section{Abbreviations}

DRG, dorsal respiratory group

nTS, nucleus tractus solitarii

PPT-A, preprotachykinin-A

STR, striatum

E31, $1 \mathrm{~d}$ before expected delivery

P0, day of birth

P1... P8, number of days after birth

Birth is a momentous event for the fetus. The ability to cope in the new environment requires the establishment of effective continuous respiration. Although the fetus demonstrates breathing movements, these are episodic in nature (1). Respiration is partially inhibited at this stage and poorly controlled by metabolic needs. This inhibition has been postulated to be due to a dominance of inhibitory neuromodulators in fetal life $(2,3)$. At birth, there is an increase of excitatory neuroactive agents (4). Among the latter is the tachykinin, substance $\mathrm{P}$, which is known to stimulate respiration (5). We have earlier shown that substance $P$ causes a more pronounced increase in ventilation in the youngest animals as compared with older ones (6).

Substance P, first isolated by von Euler and Gaddum (7), belongs to a family of structurally related peptides termed the tachykinins. It is abundantly present both in the central and peripheral nervous systems (8). The other mammalian tachyki-

Received May 3, 1990; accepted October 30, 1990.

Correspondence: M. Srinivasan, The Nobel Institute for Neurophysiology, Karolinska Institutet, S-104 01 Stockholm, Sweden.

Supported in part by research grants from National Institute for Lung and Heart Diseases SRC (29) I ROI HL 39921-01, Expressen's Prenatal Foundation, Swedish National Science Research Council, Swedish Medical Research Council, No. 19X5234 , and the Heart and Lung Foundation. nins are neurokinin-A and neurokinin-B. Substance $P$ and neurokinin-A are encoded by the same gene, PPT-A. PPT-A gene undergoes alternative splicing to give rise to three forms, of which $\alpha$ PPT-A mRNA encodes only for substance P, whereas the $\beta$ and $\gamma$-PPT-A mRNA encode for both substance P and neurokinin-A $(9,10)$. A recent study demonstrated the presence of PPT-A mRNA-containing cells in the nTS and none in the cerebellum (11). Significant quantities of substance P-like immunoreactivity was found to be localized in the nTS (12), which plays an important role in the reflex transmission of visceral afferent inputs.

The region of the nTS has been shown to receive multiple inputs from peripheral sources such as respiratory, cardiovascular, gustatory, and gastrointestinal systems via the V, VII, IX, and $X$ cranial nerves $(13,14)$. Substance $P$, which is abundant in nTS, is known to mediate baro- and chemoreceptor inputs to the nTS; hypoxic provocation results in an increased release of substance $\mathrm{P}$ in the region of nTS (15). Denervation of the IX and $X$ cranial nerves decreases the immunoreactivity for substance $P$ in the nTS (16). Thus, substance P has been suggested to have a significant physiologic role in chemo- and baroreceptor transduction mechanisms.

Two distinct populations of substance P-immunoreactive neurons have been described in the ventrolateral medulla: $l$ ) a rostral group situated ventral to the facial nucleus and 2) a caudal group lying ventrolaterally spanning the rostro-caudal length of the inferior olivary nucleus (17). In a developmental study on substance $\mathrm{P}$ immunoreactivity in the rabbit nTS using the technique of RIA, higher levels have been shown in younger animals than in adults (18). However, the time points just around birth are lacking in this study. Therefore, a study on the ontogenetic expression of PPT-A mRNA was undertaken especially around the period of birth in rabbit pups. Rabbits, which are known to be precocial developers, closely resemble human infants with regard to the maturation of sleep-wakefulness cycles (19).

\section{MATERIALS AND METHODS}

Animals. Rabbit pups of various ages (E31, P0, P1, P3, P8, and adult) were killed with an overdose of pentobarbital. The following regions, depicted in Figure 1, were rapidly dissected out, frozen on dry ice, and stored at $-70^{\circ} \mathrm{C}$ until processed further: 1) the DRG containing the region of the nTS (however, it should be noted that this area does not specifically contain only nTS and such a resolution could have been obtained by combining with in situ hybridization) where the chemoreceptor afferents terminate; 2) the ventral medullary surface structures where the central chemoreceptors are thought to be located; 3) STR as a hybridizing control; and 4) cerebellum as a negative control area.

In the second set of experiments, pregnant rabbits were anes- 
thetized and pups were delivered by cesarean section a day before estimated delivery. Half the pups in the litter were immediately killed, whereas the rest of the pups were placed in a warm environment and allowed to breathe for $2 \mathrm{~h}$.

Prior permission from the Animal Ethical Committee, Stockholm, was obtained for carrying out these experiments.

$R N A$ preparation and blot analysis. The dissected regions from four to six pups were pooled for each age. Frozen tissue samples were homogenized with a Polytron in $4 \mathrm{M}$ guanidine isothiocyanate, $0.1 \mathrm{M} \beta$-mercaptoethanol, $0.025 \mathrm{M}$ sodium citrate, $\mathrm{pH}$ 7.0. Each homogenate was layered over a 4-mL cushion of 5.7 $\mathrm{M} \mathrm{CsCl}$ in $0.025 \mathrm{M}$ sodium citrate, $\mathrm{pH} 5.5$, and centrifuged at $15^{\circ} \mathrm{C}$ in a Beckman SW41 rotor at $35000 \mathrm{rpm}$ for $21 \mathrm{~h}(20)$. The recovery of RNA was quantified spectrophotometrically before use in RNA blot analysis. RNA from each sample $(30-50 \mu \mathrm{g})$ was electrophoresed in $1 \%$ agarose gels containing $0.7 \%$ formaldehyde and transferred to nitrocellulose filters as previously described (21). The filters were prehybridized in $4 \times \operatorname{SSC}(1 \times$ $\mathrm{SSC}=0.15 \mathrm{M} \mathrm{NaCl}, 0.015 \mathrm{M}$ sodium citrate $\mathrm{pH} 7.0) 40 \%$ formamide, $1 \times$ Denhardt's solution, $10 \%$ dextran sulphate, and 150 $\mu \mathrm{g} / \mathrm{mL}$ of denatured sheared single-stranded salmon sperm DNA for $1 \mathrm{~h}$ at $43^{\circ} \mathrm{C}$ to block nonspecific binding sites on the membrane. The filter-bound RNAs were then hybridized overnight with a 300-bp BglII-BstEII fragment from a rat PPT-A cDNA clone (22). The fragment was labeled with $\alpha-\left[{ }^{32} \mathrm{P}\right]$-deoxycytidine $5^{\prime}$-triphosphate by nick-translation to a sp act of approximately $5 \times 10^{8} \mathrm{cpm} / \mu \mathrm{g}$. The filters were washed at reduced stringency $(0.5 \times$ SSC containing $0.1 \%$ SDS $)$ at $45^{\circ} \mathrm{C}$ and exposed to Kodak $\mathrm{X}$-AR5 film at $-70^{\circ} \mathrm{C}$. Autoradiograms were quantified using a Shimadzu (Tokyo, Japan) CS-9000 densitometer. The filters were subsequently boiled for $5 \mathrm{~min}$ in $1 \%$ glycerol and then probed with a nick-translated $1.5-\mathrm{kb}$ PstI fragment encoding mouse $\alpha$-actin (23). The level of PPT-A mRNA in each sample was then normalized relative to the level of actin mRNA.

\section{RESULTS}

In the region of the DRG, a $380 \%$ increase was seen in the level of PPT-A mRNA on P0 when compared with E31 (Fig. $2 A$ and $B$ ). However, on P1 there was a decrease by $25 \%$ and a further decrease was seen on P3. Although the PPT-A mRNA expression increased on P8, the adult levels were lower than postnatal values, which agrees with RIA studies in the rabbit (18) and immunohistochemical findings in the rat (24). A different ontogenetic pattern was seen in the ventral medullary surface structures. Here the prenatal expression was higher than on the day of birth, then decreased until $\mathrm{P} 1$, and thereafter gradually increased until adulthood (fig. $2 A$ and $B$ ). In the striatum, there was only a $50 \%$ increase on P0 when compared with E31 (Fig.

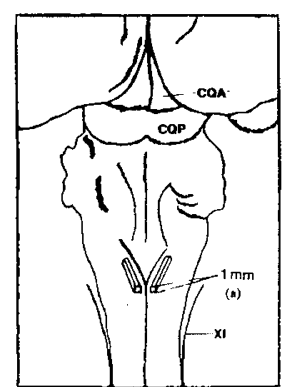

DORSAL VIEW

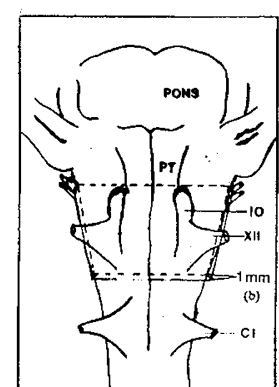

VENTRAL VIEW
Fig. 1. Drawing of the dorsal and ventral surfaces of the brain stem. The outline marked as $1 \mathrm{~mm}$ was the area and thickness of this tissue removed for Northern blot analysis. Dorsal view: $C Q A$, corpora quadrigemina anteriora; $C Q P$, corpora quadrigemina posteriora; $X I$, nervus accessorius; (a), DRG. Ventral view: $P T$, pyramidal tract; $I O$, inferior olivary nucleus; $X I I$, nervus hypoglossus; $C l$, nervus cervicalis primus; (b), ventral medullary surface structure.
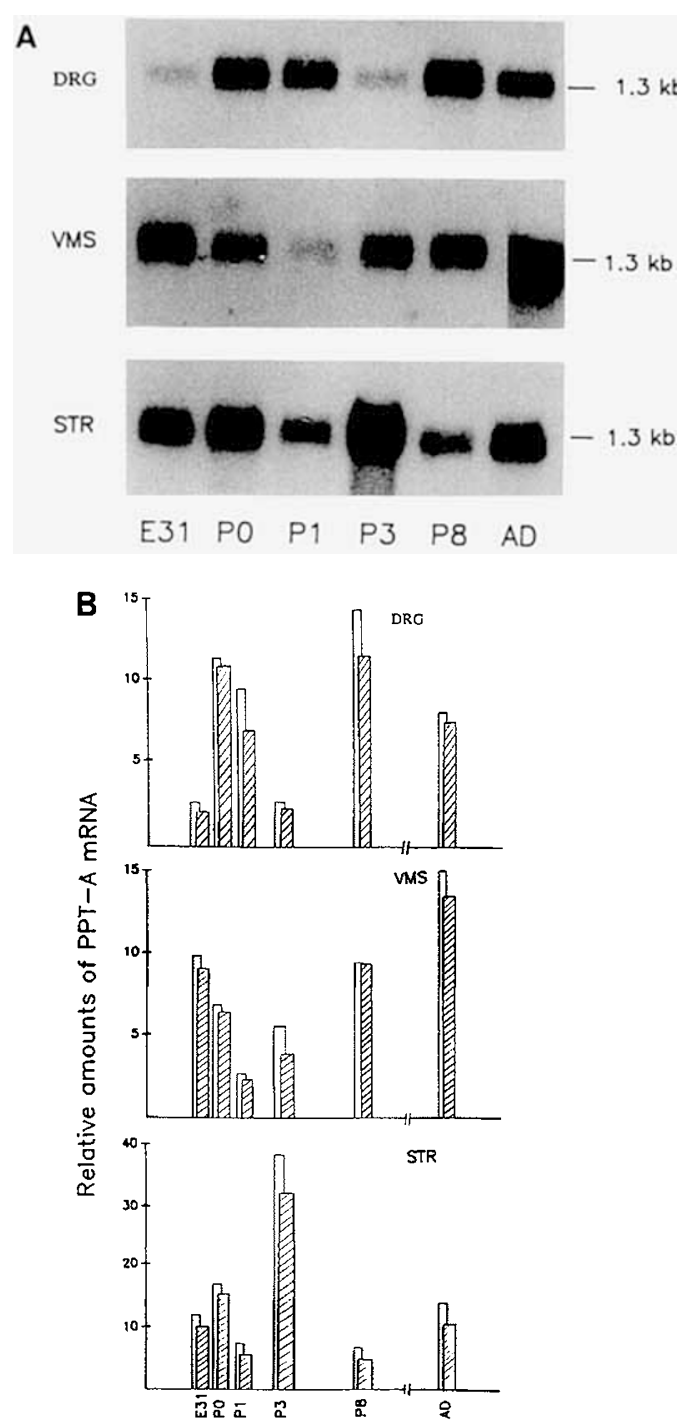

Fig. 2. Ontogenetic pattern of expression of PPT-A mRNA in DRG, ventral medullary surface structure $(V M S)$, and STR. $A$, total RNA prepared from the above areas, at the indicated developmental ages, was subjected to electrophoresis in a formaldehyde-containing agarose gel followed by transfer to a nitrocellulose filter. The filter was hybridized to a ${ }^{32} \mathrm{P}$-labeled rat PPT-A cDNA probe using $2.5 \times 10^{7} \mathrm{cpm}$ of the probe $(50 \mathrm{ng})$ followed by washing and autoradiography. $\mathrm{AD}$, adult. $B$, developmental pattern of relative amounts of PPT-A mRNA in DRG ventral medullary surface structure (VMS) and STR. Densitometric scannings were performed from two independent experiments as depicted above, one of which is shown in $A$. In each experiment, the amount of PPT-A mRNA was normalized to the level of actin mRNA. $D R G$ : An enhanced expression is seen on $\mathrm{P} 0$ as compared with E31. VMS: Prenatal expression is higher than on the day of birth. STR: The increased expression seen at $\mathrm{P} 0$ as compared with $\mathrm{E} 31$ is lower as compared with the DRG region.

$2 A$ and $B$ ). In agreement with previous in situ hybridization studies (11), no PPT-A mRNA was detected in the cerebellum.

The level of PPT-A mRNA in the region of DRG from pups delivered by cesarean section and not allowed to breathe was closely similar to the level of PPT-A mRNA observed at E31 in the ontogenetic study reported above. However, the DRG region from the pups that had breathed for $2 \mathrm{~h}$ showed a $370 \%$ increase in the level of PPT-A mRNA as compared with their nonbreathing littermates (Fig. 3). This is similar to the $380 \%$ increase seen at P0 compared with E31 in the ontogenetic study of the DRG region (Fig. $2 B$ ). No difference between the two groups was seen in the STR (Fig. 3). 


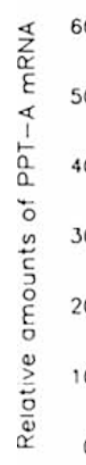

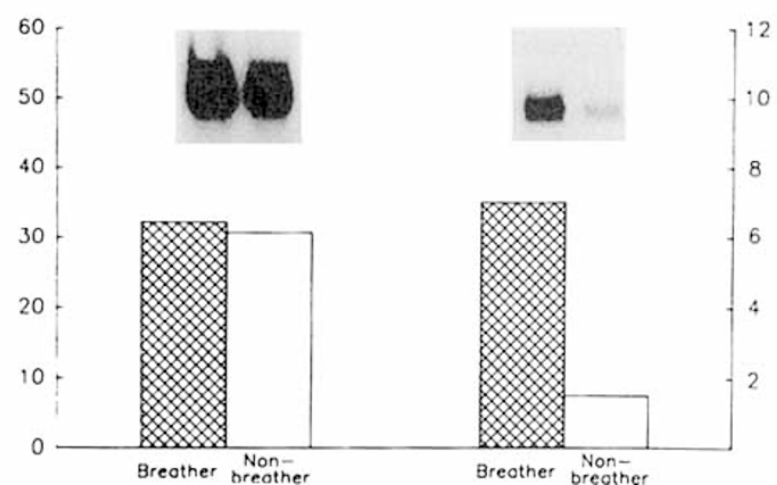

Fig. 3. Breathing-induced changes in PPT-A mRNA expression at birth. Total RNA was prepared, electrophoresed, and transferred to nitrocellulose filters as described in Fig. $2 A$. Densitometric scannings were performed as described in Fig. $2 B$. DRG: The level of PPT-A mRNA was enhanced approximately 4-fold in the breathers as compared with the nonbreathers. STR: There was no change in the level of PPT-A mRNA between the two groups.

\section{DISCUSSION}

The regulation of respiration involves complex interactions of various brainstem nuclei. Conventionally, the major neural structures concerned with the regulation of breathing are located in the medulla in the regions of the nTS, retrofacialis, para- and retroambigualis nuclei, the paragiganto-cellular nuclei involving the structures bordering the ventral surface of the medulla and also the pontine parabrachial area (13).

The results presented here are the first evidence that the expression of mRNA encoding a neuromodulator is enhanced in the first few hours after birth. Earlier studies suggest that the substance P-neuron system develops during the prenatal period of ontogeny (25), long before the establishment of normal synaptic transmission in this area (26). In a study of the developmental characteristics of substance $P$ immunoreactivity within specific brainstem nuclei in the rabbit (18), it was shown that substance $P$ immunoreactivity is highest in the nTS. Higher levels of substance $P$ immunoreactivity were demonstrated postnatally, with a peak at P7 as compared with $4 \mathrm{~d}$ before expected delivery in the nTS (18), but the time points just around the period of birth were not studied. Immunohistochemical studies demonstrate only the level of neuropeptides, which are the net results of synthesis and processing. On the other hand, by analyzing mRNA levels we can directly follow the changes in gene activity that may be the underlying mechanism for the changes in peptide levels.

The peripheral chemoreceptors are active in the fetus in late gestation, but it is interesting to note that peripheral chemodenervation does not affect the incidence of fetal breathing movements (27). The control mechanisms behind the switch from intermittent fetal breathing to continuous postnatal breathing have not yet been elucidated. There appears to be a preponderance of inhibitory transmitters during fetal life, but their effect may be overcome at birth by excitatory neuromodulators like substance $P$. The question of whether or not the increased expression of the gene for substance $P$ is essential for the control of breathing at birth cannot yet be answered. The fluctuating phenomena seen in the expression of the PPT-A gene, especially in the areas of DRG and STR, suggest either the inhibition of operation of negative feedback loops or the lack of precision of negative control by the known inhibitory neuromodulators of respiration (opioids, dopamine) after birth. However, the fluctuation seen at birth in the area of DRG has been more closely examined and an enhanced expression of PPT-A mRNA was shown to occur $2 \mathrm{~h}$ after birth (Fig. 3). The enhanced expression of the PPT-A gene in DRG at the transition from intrauterine to extrauterine life may also be associated with either an increase in $\mathrm{PO}_{2}$ levels or an enhancement in sensory inputs from various peripheral sensors, including lung receptors.

Acknowledgment. The authors thank Dr. S. Nakanishi (Kyoto, Japan) for the kind gift of PPT-A cDNA clone.

\section{REFERENCES}

1. Boddy K, Dawes GS, Fisher R, Pinter S, Robinson S 1974 Foetal respiratory movements, electrocortical and cardiovascular responses to hypoxemia and hypercapnia in sheep. J Physiol (Lond) 243:599-618

2. Lagercrantz H 1987 Neuromodulators and respiratory control during development. Trends Neurosci 10:368-372

3. Moss IR, Denavit-Saubie M, Eldridge FL, Gillis RA, Herkenham M, Lahiri S 1986 Neuromodulators and transmitters in respiratory control. Fed Proc 45:2133-2147

4. Lagercrantz H, Slotkin TA 1986 The "stress" of being born. Sci Am 254:100107

5. von Euler US, Pernow B 1956 Neurotropic effects of substance P. Acta Physiol Scand 36:265-275

6. Yamamoto Y, Lagercrantz H 1985 Some effects of substance P on central respiratory control in rabbit pups. Acta Physiol Scand 124:449-455

7. von Euler US, Gaddum JH 1931 An unidentified depressor substance in certain tissue extracts. J Physiol (Lond) 72:74-87

8. Nicoll RA, Schenker C, Leeman SE 1980 Substance P as a neurotransmitter candidate. Annu Rev Neurosci 3:227-268

9. Nawa H, Kotani $H$, Nakanishi $S 1984$ Tissue specific generation of two preprotachykinin mRNAs from one gene by alternative RNA splicing. Nature 312:729-734

10. Krause JE, Chirgwin JM, Carter MS, Xu ZS, Hershey AD 1987 Three rat preprotachykinin $m$ RNAs encode the neuropeptides substance $P$ and neurokinin A. Proc Natl Acad Sci USA 84:881-885

11. Warden MK, Young III SW 1988 Distribution of cells containing mRNAs encoding substance $\mathrm{P}$ and neurokinin $\mathrm{B}$ in the rat central nervous system. $\mathrm{J}$ Comp Neurol 272:90-113

12. Maley B, Elde R 1982 Immunohistochemical localization of putative neurotransmitters within the feline nucleus tractus solitarii. Neuroscience 7:24692490

13. von Euler C 1986 Brain stem mechanisms for generation and control of breathing pattern. In: Cherniack NS, Widdicombe JG (eds) Handbook of Physiology: Section 3, The Respiratory System, Pt 1, Vol 2. American Physiological Society, Bethesda, MD, pp 1-67

14. Kerr FWL 1962 Facial, vagal and glossopharyngeal nerves in the cat. Afferent connections. Arch Neurol Psychiatry 6:264-281

15. Lindefors N, Yamamoto Y, Pantaleo T, Lagercrantz H, Brodin E, Ungersted $\mathrm{U} 1986$ In vivo release of substance $\mathrm{P}$ in the nucleus tractus solitarii increases during hypoxia. Neurosci Lett 69:94-97

16. Gillis RA, Helke CJ, Hamilton BL, Norman WP, Jacobowitz DM 1980 Evidence that substance $P$ is a neurotransmitter of baro- and chemo-receptor afferents in nucleus tractus solitarii. Brain Res 181:476-481

17. Marson L, Loewy AD 1985 Topographic organization of substance $P$ and monoamine cells in the ventral medulla of the cat. J Auton Nerv Syst $14: 271-285$

18. Gingras JL, Brunner SL. McNamara MC 1988 Developmental characteristics of substance $P$ immunoreactivity within specific rabbit brainstem nuclei. Regul Pept 23:183-192

19. Shimizu A, Himwick HE 1968 The ontogeny of sleep in kitten and young rabbits. Electroencephalogr Clin Neurophysiol 24:307-318

20. Chirgwin J, Aeyble A, McDonald R, Rutter W 1979 Isolation of biologically active ribonucleic acid from sources enriched in ribonuclease. Biochemistry 18:5294-5299

21. Whittemore SR, Ebendal T, Lärkfors L, Olsson L, Seiger A, Strömberg I Persson H 1986 Developmental and regional expression of nerve growth factor messenger RNA and protein in the rat central nervous system. Proc Natl Acad Sci USA 83:817-821

22. Kawaguchi Y, Hoshimaru M, Nawa H, Nakanishi S 1986 Sequence analysis of cloned $C D N A$ for rat substance $P$ precursor: existence of a third substance $P$ precursor. Biochem Biophys Res Commun 139:1040-1046

23. Minty AJ, Caravatti M, Benvit K, Cohen A, Danbas P, Weydert A, Gros F, Buckingham ME 1981 Mouse actin messenger RNAs: construction and characterization of a recombinant plasmid molecule containing a complementary DNA transcript of mouse $\alpha$-actin mRNA. J Biol Chem 256:1008mentary

24. Ljungdahl $\dot{A}$, Hökfelt T, Nilsson G 1978 Distribution of substance P-like immunoreactivity in the central nervous system of the rat. $I$. Cell bodies and nerve terminals. Neuroscience 3:861-943

25. Sakanaka M, Inagaki S, Shiosaka S, Senba E, Takagi H, Takatsuki K, Kawai Y, lida H, Hara Y, Tohyama M 1982 Ontogeny of substance P containing neuron system of the rat: immunohistochemical analysis II. Lower brain stem. Neuroscience 7:1097-1126

26. Altman J, Bayer SA 1980 Development of the brain stem in the rat-II. Thymidine-radiographic study of the time of origin of neurons of the upper medulla, excluding the vestibular and auditary nuclei. J Comp Neurol 194:37-56

27. Moore PJ, Parkes MJ, Nijhuis JG, Hanson MA 1989 The incidence of breathing movements of foetal sheep in normoxia and hypoxia after peripheral chemodenervation and brain stem transection. J Dev Physiol 1 $1: 147-151$ 


\title{
The Natural History of the Appearance of Apnea of Prematurity
}

\author{
KEITH BARRINGTON AND NEIL FINER \\ Walter Mackenzie Health Sciences Center, Division of Newborn Medicine, University of Alberta Hospitals, \\ Edmonton, Alberta, Canada T6G 2B7 [K.B.] and Division of Newborn Medicine, Royal Alexandra Hospitals,
} Edmonton, Alberta, Canada T5H 2 V9 [N.F.]

\begin{abstract}
Twenty healthy preterm infants of less than 34 wk gestation were studied with continuous recordings, commencing within $8 \mathrm{~h}$ of birth, for up to 1 wk of age to determine the usual time course of the appearance of apnea and to classify apnea types. Airway occlusion studies were also performed on a regular basis to determine whether apneic spells were preceded or followed by a reduction in central respiratory drive. Apneic spells of greater than $\mathbf{1 5}$ $s$ duration accompanied by hypoxia or bradycardia occurred in all infants before $24 \mathrm{~h}$ of age. The frequency of apneic spells was highest in the first $24 \mathrm{~h}$ after birth with a mean frequency of $0.9 / \mathrm{h}$ and gradually reduced thereafter, falling to $0.2 / \mathrm{h}$ by $5 \mathrm{~d}$ of age $(p<0.01)$. Apneic spells were more likely to be obstructive in the first $2 \mathrm{~d}$ of life than thereafter $(p<0.05)$. Central apnea was proportionately significantly less frequent during this time period. Reduced respiratory drive, as demonstrated by airway occlusion pressures, was associated with more frequent apnea and was evident at the first occlusion study, which frequently preceded the first significant apnea. (Pediatr Res 29: 372-375, 1991)
\end{abstract}

\section{Abbreviations}

$\mathrm{SpO}_{2}$, pulse oximeter-derived saturation

$P_{0.1}$, airway pressure $0.1 \mathrm{~s}$ after initiation of first occluded breath

ANOVA, analysis of variance

It is commonly stated that idiopathic apnea of prematurity develops after the first 24 to $72 \mathrm{~h}$ of life and apnea that is noted early requires vigorous investigation (1). The factual basis of this statement is uncertain. Henderson-Smart (2) previously demonstrated that apnea (more than three spells of greater than $20 \mathrm{~s}$ duration) developed on the 1 st or 2 nd postnatal $d$ in $77 \%$ of preterm infants. He appears to have used impedance monitoring only and it is uncertain whether any recordings were made for independent confirmation of apnea (3). Carlo et al. (4), utilizing 60 -min recordings, showed that apneic spells of greater than $5 \mathrm{~s}$ duration occurred on $d 1$ in eight of 10 preterm infants without lung disease.

There appears to be no published information regarding the usual frequency and nature of significant apneic spells in an unselected population of healthy newborn preterm infants who have undergone prolonged recordings.

Our main objective was to ascertain the usual age of the

Received March 28, 1990; accepted December 5, 1990.

Reprint requests: Dr. K. Barrington, 3A3 Walter Mackenzie Health Sciences Center, Division of Newborn Medicine, University of Alberta Hospitals, Edmonton, Alberta, Canada T6G 2B7.

Supported by the Northern Alberta Children's Hospital Foundation. appearance of apneic spells and the relative frequency of obstructive, mixed, and central apnea during the $1 \mathrm{st}$ wk of life in preterm infants without respiratory disease. Our secondary objective was to describe the development of respiratory drive, by determining the postnatal progression of occlusion pressures, in infants with and without apnea.

\section{SUBJECTS AND METHODS}

Twenty infants of less than 34 wk gestation with birth weights above the 5 th percentile for gestational age were studied. Infants were all born in the Royal Alexandra Hospitals and were entered into the study as soon after birth as possible. We entered consecutive infants who were clinically determined to be free of acute medical problems; in particular, they were without significant respiratory disease. The criteria for this were an oxygen requirement of no more than $30 \%$, respiratory rate less than $70 / \mathrm{min}$, and no clinical suspicion of pneumonia or hyaline membrane disease. Infants requiring any supplemental oxygen had chest radiographs, which were required to be normal. Ultrasound examination of the head was performed in all infants before $4 \mathrm{~d}$ of age and again at approximately 2 wk of age. Any infant with intraventricular hemorrhage that distended the ventricles or evidence of intracerebral hemorrhage or periventricular leukomalacia on either examination was eliminated from the study.

After the initial clinical examination and assessment to ensure that the infants were stable, each was monitored with a combination of impedance pneumogram, for the detection of chest wall movement, ECG, pulse oximetry $\left(\mathrm{SpO}_{2}\right)$, and end-tidal $\mathrm{CO}_{2}$ monitoring; some infants were monitored with transcutaneous $\mathrm{PO}_{2}$ in addition. The analogue outputs of each of these monitors was digitized by a Data-translation DT2800 analogue to digital convertor board (Data Translation, Inc., Marlborough, MA) and then analyzed on a Compaq 286 personal computer (Compaq Computer Corp., Houston, TX), using programs that we wrote using the Asyst programming language (Asyst Software Industries, Rochdale, NY).

At this point, parental consent was sought for the airway occlusion studies and for the continuance of noninvasive monitoring. In the event of parental refusal of the occlusions, consent for continued monitoring alone was requested. This protocol was approved by the clinical investigation committee of the Royal Alexandra Hospitals.

After obtaining consent, airway occlusions were performed as previously described (5). A face mask was applied and the absence of leaks was confirmed. Airflow was monitored by means of a Fleisch 00 pneumotachograph and integrated electronically to give tidal volume. At end-expiration the airway was occluded and during the next breath the resultant airway pressures were recorded. The $P_{0.1}$ was recorded. Three occlusion responses were obtained on each occasion and averaged. This process was performed as soon as possible after birth and then every $12 \mathrm{~h}$ for 
the next $72 \mathrm{~h}$. Thereafter, occlusions were performed daily until the study terminated.

The study continued until the infant was 1 wk old or until therapy (theophylline) for idiopathic apnea of prematurity was prescribed by the attending physician. Thus, all of the results presented herein are from infants who were not receiving methylxanthines or any other therapy for apnea. The clinical staff had no knowledge of the results of the recordings and clinical diagnosis of apnea was according to the usual unit practice of examination of the nursing records.

At the termination of the study, the recordings were analyzed by means of a semiautomated process (6). The program used will flag an epoch that is considered to contain a potential apneic spell by looking for a combination of any two of the following: loss of end-tidal $\mathrm{CO}_{2}$, fall in heart rate, and fall in $\mathrm{SpO}_{2}$. The epoch may then be visually inspected to determine whether a significant apneic spell was present. The criteria for the diagnosis of a significant apneic spell were as follows: lack of nasal airflow for $15 \mathrm{~s}$ accompanied by either a fall in heart rate $20 \%$ below the previous mean heart rate or a fall in $\mathrm{SpO}_{2}$ of 10 percentage points. When a spell was identified, its duration and time of occurrence were noted and it was classified into central, obstructive, or mixed. Central spells were those in which there were no obstructed breaths during the apnea. The presence of one or more obstructed respiratory efforts prompted the diagnosis of a mixed or obstructive apneic spell, which were further differentiated by the presence of a period of absent chest wall movement of at least 3 to $4 \mathrm{~s}$ duration.

Apnea frequency was calculated on a daily basis. For the first $24 \mathrm{~h}$, the apnea frequency was calculated as the number of apneas noted before $24 \mathrm{~h}$ of age divided by the number of hours of recording performed. Thereafter, the apnea frequency was calculated by dividing the daily number of apneas by 24 .

Statistical methods included a two-way ANOVA to compare frequencies of apnea with respect to apnea types and postnatal age, with a protected Fisher's least significant difference being used as the post hoc test to define intergroup differences in the event of a significant ANOVA. Pearson correlation coefficient was used to determine the significance of the relationship between apnea frequency and occlusion pressures.

Some data from 10 of these infants has been previously reported (6) (incidence of periodic breathing and relationship between periodicity and apnea).

\section{RESULTS}

The 20 infants were studied commencing at a mean age of 3.8 h (range 2 to 8 ). Their mean birth weight was $1012 \mathrm{~g}$ (SD 322) and mean gestation was $29.7 \mathrm{wk}$ (SD 2.7). Thirteen infants were delivered by the vaginal route and seven by cesarean section. The first head ultrasound revealed six infants with subependymal hemorrhages. Two of these infants progressed to small intraventricular hemorrhages. Three infants required supplemental oxygen when first entered into the study to maintain an $\mathrm{SpO}_{2}$ of greater than $92 \%$; all were in room air by $12 \mathrm{~h}$ of age.

All infants in the study experienced significant apneic spells before $24 \mathrm{~h}$ of age. The mean age of the first recorded apnea was $8.5 \mathrm{~h}$ (SD 3.6, range 3 to 18 ), which was a mean of $4.7 \mathrm{~h}$ (SD 4.0 ) after initiating the recording. The daily distribution of apneic spells is shown in Figure 1. When the daily apnea rates were compared, there was a significant difference in total apnea frequency between $\mathrm{d} 1$ and $\mathrm{d} 4$ to 7 (ANOVA, $F_{6,133}=3.2, p<$ $0.01)$ Table 1 . Obstructive and mixed apneas were significantly more frequent on $\mathrm{d} 1$ than on $\mathrm{d} 4$ to $7(p<0.05)$. Central apneic spells were not significantly different in frequency between any $2 \mathrm{~d}$; thus, the proportions of types of apneic spells were significantly different between $\mathrm{d} 1$ and $\mathrm{d} 4$ to $7\left(\chi^{2} p<0.05\right)$.

Thirteen of the infants were diagnosed as having clinical apnea during the 1 st wk of life and all were treated with theophylline. Seven of the infants therefore had recordings for the entire 1st wk of life. None of the infants were removed from the study before $\mathrm{d} 4$, three were excluded on $\mathrm{d} 5$, seven on $\mathrm{d} 6$, and three on $\mathrm{d} 7$. There were no significant differences in apnea frequency or apnea subtype distribution between $\mathrm{d} 4$ and $\mathrm{d} 7$.

We wished to determine whether there was a threshold number, or duration, of apneic spells that would trigger clinical recognition of apnea and subsequent treatment. On $\mathrm{d} 4,5$, and 6 of the study there were, therefore, a group of infants who received therapy the next day (and were then removed from the study) and a group of infants that were not treated next day. On each of the $3 \mathrm{~d}$, the "not treated next day" infants included the seven who never received therapy (Table 2). Apnea frequency was therefore compared between the groups, using a $t$ test with Bonferroni correction. There were no significant differences on d 4,5 , or 6 . Eight of the 13 treated infants had a work up for sepsis that included a complete blood count, blood culture, and spinal tap. All cultures were negative.

Airway occlusion studies were performed in 16 infants. The first study was performed at a mean postnatal age of $7 \mathrm{~h}$ and preceded the first recorded apnea in 12 of the infants. There was a progressive nonsignificant increase in the $P_{0.1}$ from the first to the last day of the study. There was a significant negative association $(r=-0.57, p<0.05)$ between the apnea frequency over the first three days and $P_{0.1}$ measured at the time of the first occlusion study, but a very wide scatter prevents this from being a useful predictive test (Fig. 2).

\section{DISCUSSION}

There was a $100 \%$ incidence of significant apnea in this study during the first $24 \mathrm{~h}$ of life. This contrasts with studies that used either brief (4) recordings or none at all (2) and emphasizes the importance of both continuous recordings and airflow monitoring for studies on apnea. Our findings imply that there is a $95 \%$ probability that $85 \%$ or more of clinically healthy infants of less than 34 wk gestation will have apneic spells on the first day.

We have performed a number of comparisons of our unique, purpose written programs with paper recordings at each state of development. These evaluations have demonstrated that significant apneic spells are not missed and many artefacts that a fully automated method could record as apneas are eliminated. The use of a single nasal detector could lead to problems if mouth opening or nasal blockage occurred; however, the requirement for hypoxia or bradycardia, in addition to the loss of nasal airflow, to diagnose an apnea makes this an unlikely cause for confounding of our results.

There is no generally accepted definition of what constitutes a significant apneic spell; investigators in recent years have accepted spells of $10(7), 15(8,9), 20(10)$, or $30(11)$ s duration regardless of the occurrence of other physiologic changes. It is also frequently stated that shorter apneas were considered to be significant if associated with either hypoxia or bradycardia. Our definition of apnea requires both a duration of at least $15 \mathrm{~s}$ and either hypoxia or bradycardia. If we had simply required a duration of $15 \mathrm{~s}$, regardless of hypoxia or bradycardia, we would have reported an even higher incidence of early apneic spells.

The initial objective of the study was to compare the early occlusion pressures of infants who developed apnea to control infants who did not. However, in view of the absence of nonapneic infants, we revised our planned analysis of the results. We demonstrated that occlusion pressures were lower in the infants with the most frequent apneic spells before the occurrence of the first recorded apnea. This suggests that apneic spells and reduced occlusion pressures may be caused by similar factors. Previous data from adults indicate that reduced respiratory drive may occur as a result of multiple apneic episodes, because respiratory drive gradually improves after tracheostomy $(12,13)$. Our data would not support the idea that occlusion pressures in premature infants are reduced secondarily to the physiologic effects of apneic spells. 

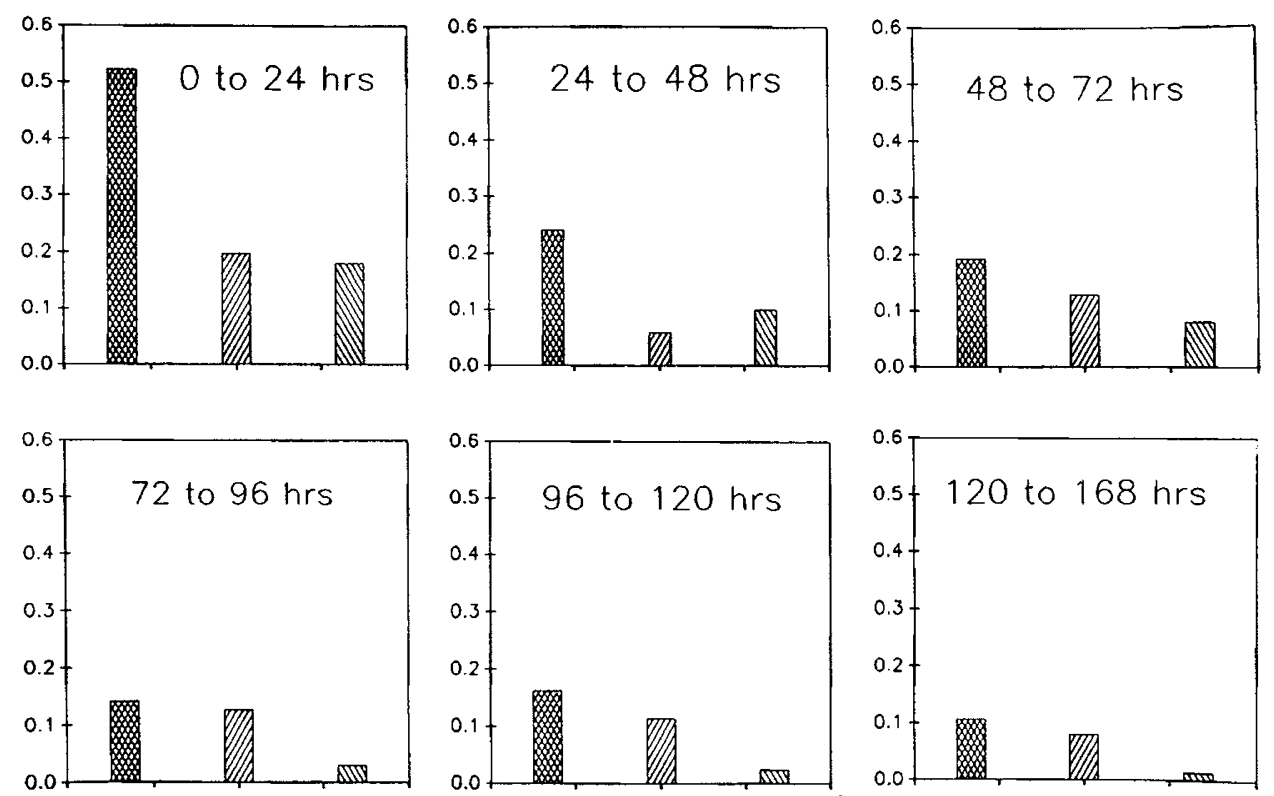

Fig. 1. Apnea frequency $(/ \mathrm{h})$ during consecutive periods after birth in 20 premature infants. Mixed apneas obstructive apneas $\mathbb{\mathbb { N }}$, and central apneas

Table 1. Mean and range of daily total apnea frequencies and apnea durations

\begin{tabular}{|c|c|c|c|c|c|c|c|}
\hline & \multicolumn{7}{|c|}{ Day } \\
\hline & 1 & 2 & 3 & 4 & 5 & 6 & 7 \\
\hline Apneas $>15 \mathrm{~s}(/ \mathrm{h})$ & 0.9 & 0.4 & 0.4 & 0.3 & 0.3 & 0.3 & 0.2 \\
\hline Maximum frequency $(/ \mathrm{h})$ & 2.1 & 2.5 & 1.6 & 2.6 & 1.1 & 1.8 & 1.7 \\
\hline Minimum frequency $(/ \mathrm{h})$ & 0.21 & 0.13 & 0.08 & 0.04 & 0.08 & 0.08 & 0.04 \\
\hline Mean duration (s) & 24.2 & 25.4 & 25.4 & 25.7 & 29.8 & 28.5 & 24.2 \\
\hline Maximum duration (s) & 49.1 & 68.2 & 50.0 & 43.2 & 49.5 & 53.1 & 32.0 \\
\hline Apneas $>20 \mathrm{~s}(/ \mathrm{h})$ & 0.6 & 0.3 & 0.2 & 0.2 & 0.1 & 0.2 & 0.1 \\
\hline
\end{tabular}

Table 2. Apnea frequency $(/ h)$ of infants treated and not treated for apnea of prematurity

\begin{tabular}{|c|c|c|c|c|c|c|c|c|c|}
\hline & \multicolumn{3}{|c|}{ Day 4} & \multicolumn{3}{|c|}{ Day 5} & \multicolumn{3}{|c|}{ Day 6} \\
\hline & $n$ & Mean & $\mathrm{SD}$ & $n$ & Mean & SD & $n$ & Mean & SD \\
\hline Treated next day & 3 & 0.47 & 0.23 & 7 & 0.35 & 0.19 & 3 & 0.24 & 0.22 \\
\hline Not treated next day & 17 & 0.26 & 0.20 & 10 & 0.28 & 0.21 & 7 & 0.31 & 0.11 \\
\hline Never treated & 7 & 0.32 & 0.14 & 7 & 0.29 & 0.18 & & & \\
\hline
\end{tabular}

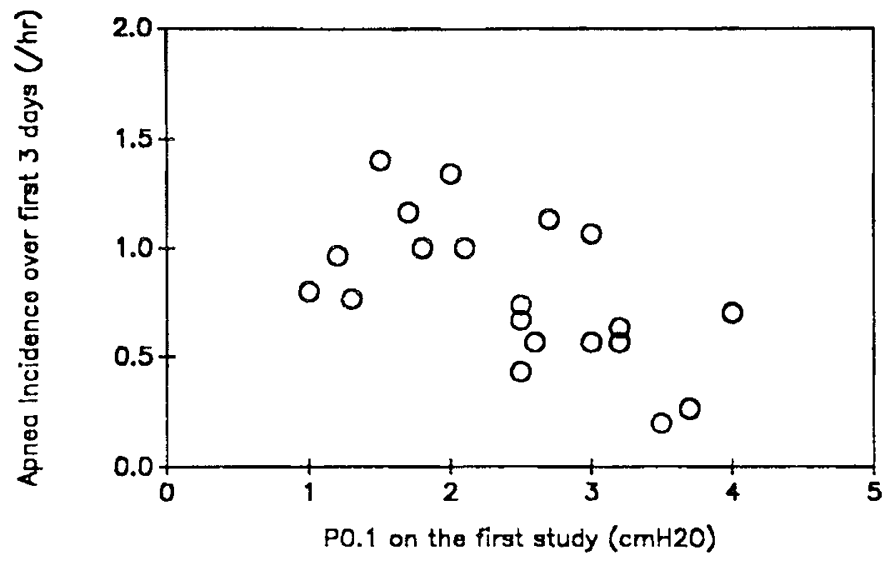

Fig. 2. Relationship between occlusion pressure $\left(\mathrm{P}_{0.1}\right)$ and apnea frequency during the first $3 \mathrm{~d}$ of life.
Airway occlusion pressures, although commonly used as an index of respiratory center output, also reflect the state of contractility of the respiratory muscles (14); the association between occlusion pressure and apnea severity could, therefore, be due to an effect of respiratory muscle contractility. Indeed, there may well be an association between fatigue of the diaphragm and apneic spells (15). We currently have no data to confirm or refute this suggestion. There is also little data on the effects of chest wall distortion on perceived occlusion pressures. It seems likely that chest wall distortion decreases measured occlusion pressures and may also be related to apneic spells because of an increase in respiratory work (16). We did not measure chest wall movement or distortion during occlusion studies.

Our finding of early apnea confirms our previous report (6) and the suggestions of Henderson-Smart (2) and Carlo et al. (4). The common assertion that idiopathic apnea of prematurity occurs later may be due to the use of thoracic impedance as the exclusive method of clinical apnea monitoring in neonatal nurseries. That is a method that will not detect obstructive apneas or the obstructive portion of mixed apneas. To detect the frequent obstructed breaths of preterm infants, a monitor of oronasal airflow, such as the nasal detection of expired $\mathrm{CO}_{2}$, is required.

The frequency of early apnea suggests that deficient immediate postnatal adaptation is etiologically related to the spells. We postulate that reduced central respiratory drive is associated with both reduced occlusion pressures and apneic spells. Central respiratory drive is dependent upon afferent input from a number of sources (17). We suggest that the documented suppression of the peripheral chemoreceptor during this interval, because of the sudden increase in arterial $\mathrm{PO}_{2}(18,19)$, could well be a cause of both reduced respiratory drive and obstructive apneas. Two 
convergent lines of evidence support this suggestion. First, arousal is required for termination of apneic spells in adults with obstructive sleep apnea (13). Activity of the carotid bodies is required for arousal in adult dogs (20) and newborn lambs (21) subjected to progressive hypoxia. Thus, carotid body inactivity could well lead to failure of arousal and to apneas becoming prolonged and more likely to be associated with hypoxia and bradycardia.

Second, the peripheral chemoreceptors appear to be particularly important in the maintenance of upper airway muscle activity. Evidence from both adult animals (22) and newborn infants (23) supports this and would suggest that during immediate postnatal adaptation maintenance of upper airway patency would be less efficient and obstructive and mixed apnea would be more common.

We were unable to demonstrate any significant differences between infants who were removed from the study because they were treated for apnea with methylxanthines and those who remained untreated. The clinical staff was not aware of the results of the computer analysis and the question of what prompted the clinicians to treat apnea remains unresolved. We assume that either the reporting of the apneic spells by the bedside nurse to the physician may have differed or the threshold that individual physicians used to treat apnea may have varied. Because of the lack of agreement concerning the outcome of infants who experience apnea of prematurity $(24,25)$, it is inevitable that such differences will persist. Further research is required to determine what severity, frequency, and type of apneic spells are associated with clinically significant impairment.

\section{REFERENCES}

1. Vyas H, Milner AD 1986 Other respiratory disorders in the neonate. In Roberton NRC (ed) Neonatology. Churchill Livingstone, Edinburgh, pp 312-339

2. Henderson-Smart DJ 1981 The effect of gestational age on the incidence and duration of recurrent apnoea in newborn babies. Aust Paediatr J 17:273276

3. Muttit S, Finer NN, Tierney AJ, Rossmann J 1988 Neonatal apnea: diagnosis by nurse versus computer. Pediatrics $82: 713-720$

4. Carlo WA, Martin RJ, Versteegh FGA, Goldman MD, Robertson SS, Fanaroff AA 1982 The effect of respiratory distress syndrome on chest wall movement and respiratory pauses in preterm infants. Am Rev Respir Dis 126:103-107

5. Barrington KJ, Finer NN, Peters KL, Barton J 1986 The physiologic effects of doxapram in idiopathic apnea of prematurity. J Pediatr 108:124-129
6. Barrington KJ, Finer NN 1990 Periodic breathing and apnea in preterm infants. Pediatr Res 27:118-121

7. Jones RAK 1982 Apnoea of immaturity. 1. Controlled trial of theophylline and face mask continuous positive airways pressure. Arch Dis Child 57:761765

8. Hiatt IM, Hegyi T, Indyk L, Dangman BC, James LS 1981 Continuous monitoring of $\mathrm{PO}_{2}$ during apnea of prematurity. J Pediatr 98:288-291

9. Boros SJ, Reynolds JW 1976 Prolonged apnea of prematurity: treatment with continuous distending pressure delivered by nasopharyngeal tube. Clin $\mathrm{Pe}$ diatr (Phila) 15:123-134

10. Gerhardt T, Bancalari E 1984 Apnea of prematurity: 1. Lung function and regulation of breathing. Pediatrics 74:58-62

11. Lagercrantz H, Rane A, Tunell R 1980 Plasma concentration-effect relationship of theophylline in treatment of apnea in preterm infants. Eur $\mathrm{J}$ Clin Pharmacol 18:65-68

12. Guilleminault C, Cummiskey J 1982 Progressive improvement of apnea index and ventilatory response to $\mathrm{CO}_{2}$ after tracheostomy in obstructive sleep apnea syndrome. Am Rev Respir Dis 126:14-20

13. Bradley TD, Phillipson EA 1985 Pathogenesis and pathophysiology of the obstructive sleep apnea syndrome. Med Clin North Am 69:1169-1185

14. Aubier M, Murciano D, Viires N, Lecoguic Y, Palcios S, Pariente R 1983 Increased ventilation caused by improved diaphragmatic efficiency during aminophylline infusion. Am Rev Respir Dis 127:148-154

15. Lopes JM, Muller NL, Bryan MH, Bryan AC 1981 Synergistic behavior of inspiratory muscles after diaphragmatic fatigue in the newborn. $J$ Appl Physiol 51:547-551

16. Guslits BG, Gaston SE, Bryan MH, England SJ, Bryan AC 1987 Diaphragmatic work of breathing in premature human infants. I Appl Physiol 62:14101415

17. Sullivan CE, Kozar LF, Murphy E, Phillipson EA 1978 Primary role of respiratory afferents in sustaining breathing rhythm. J Appl Physiol 45:1117

18. Belenky DA, Standaert TA, Woodrume DE 1979 Maturation of hypoxic ventilatory response of the newborn lamb. J Appl Physiol 47:927-930

19. Hertzberg T, Lagercrantz H 1987 Postnatal sensitivity of the peripheral chemoreceptors in newborn infants. Arch Dis Child 62:1238-124

20. Bowes G, Townsend ER, Kozar LF, Bromley SM, Phillipson EA 1981 Effect of carotid body denervation on arousal response to hypoxia in sleeping dogs. J Appl Physiol 51:40-45

21. Fewell JE, Kondo CS, Dascalu V, Filyk SC 1989 Influence of carotid denervation on the arousal and cardiopulmonary response to rapidly developing hypoxaemia in lambs. Pediatr Res 25:473-477

22. Bruce EN, Mitra J, Cherniack NS 1982 Central and peripheral chemoreceptor inputs to phrenic and hypoglossal motoneurones. J Appl Physiol 53:15041511

23. Carlo WA, DiFiore JM, Martin RJ 1989 Increased upper airway muscle activity during hypoxaemia-induced respiratory depression in preterm infants. Pediatr Res 25:373A(abstr)

24. Jones RAK, Lukeman D 1982 Apnoea of immaturity. 2. Mortality and handicap. Arch Dis Child 57:766-768

25. Levitt GA, Mushin A, Bellman S, Harvey DR 1988 Outcome of preterm infants who suffered neonatal apneic attacks. Early Hum Dev 16:235-243 